\title{
Banheiros pré-fabricados: seus benefícios e como criam valor para consumidores
}

\author{
Prefabricated bathroom pods: benefits and how they \\ create value for consumers
}

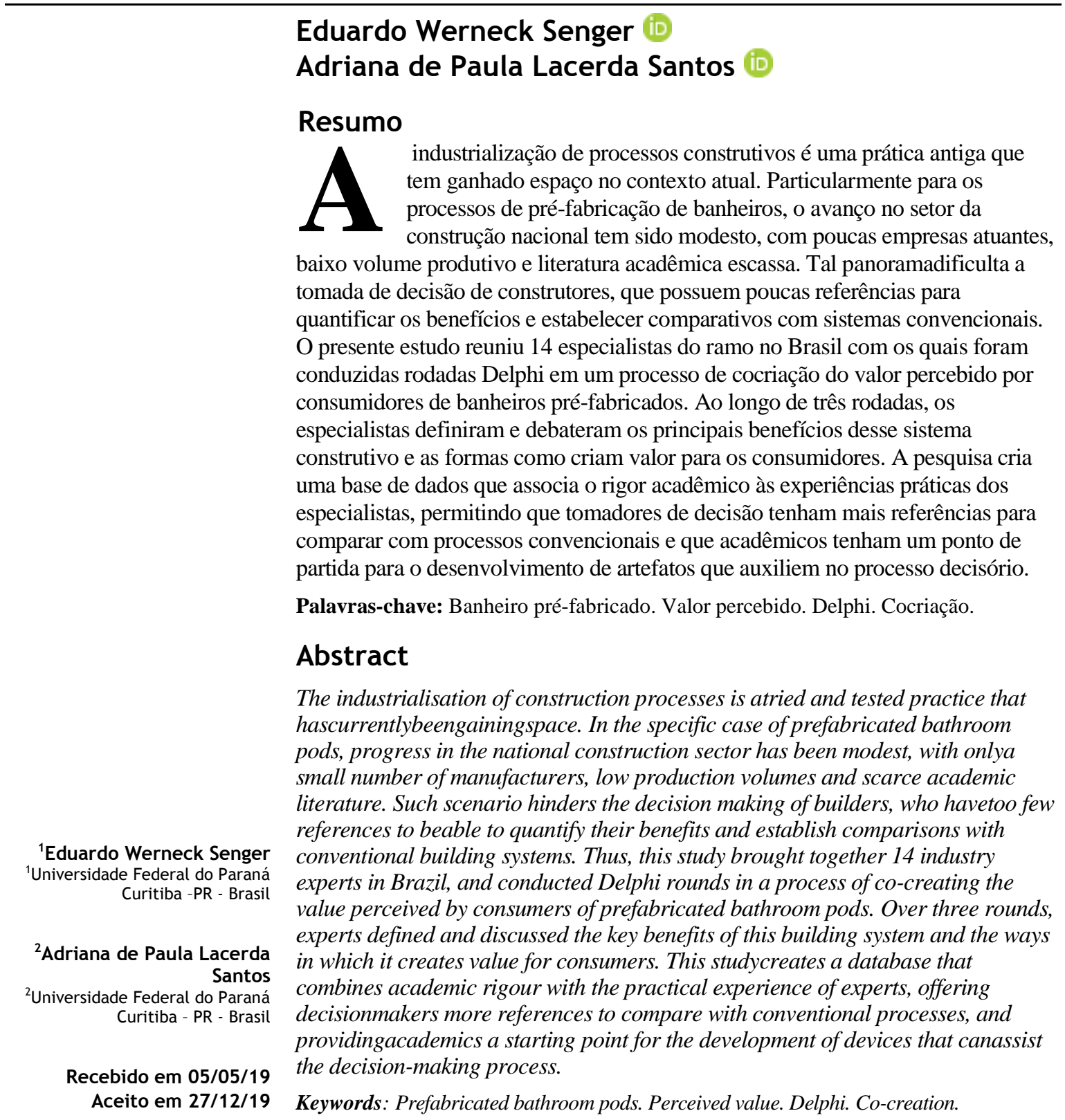

SENGER, E. W.; SANTOS, A. de P. L. Banheiros pré-fabricados: seus benefícios e como criam valor para consumidores. 573 Ambiente Construído, Porto Alegre, v. 20, n. 3, p. 573-589, jul./set. 2020. ISSN 1678-8621 Associação Nacional de Tecnologia do Ambiente Construído. http://dx.doi.org/10.1590/s1678-86212020000300446 


\section{Introdução}

O setor da construção civil brasileira é reconhecido pela baixa produtividade, seja em comparação com a média dos demais setores, seja em relação ao cenário internacional. Tal panorama foi registrado peloSinduscon (SINDICATO..., 2015), o qual conclui que, apesar do aquecimento setorial entre 2003 e 2013 , a produtividade da construção brasileira manteve-se praticamente estática nesse período e 31,8\% inferior à média da economia. Ainda, apresentou produtividade correspondente a $23 \%$ da média do mesmo setor em países desenvolvidos.

A industrialização pode ser empregada em diferentes fases e processos construtivos de um empreendimento e posiciona-se como uma alternativa para proporcionar ganhos de produtividade no setor. Tal potencial foi verificado por Shahzad, Mbachuee Domingo (2015), que coletaram dados de 66 edificações construídas na Nova Zelândia com técnicas industrializadas e compararam os custos e tempos de execução com estimativas para construções similares executadas com métodos convencionais. A comparação resultou em 34\% e 19\% de reduções médias no tempo para conclusão e custos respectivamente. Esse ganho foi traduzido em um aumento de $7 \%$ na produtividade média dos projetos.

Como a construção de banheiros em edificações convencionais compreende uma das atividades mais complexas e custosas de um empreendimento (VOKES; BRENNAN, 2013), técnicas de pré-fabricação de banheiros têm sido difundidas mundialmente. Em relatório detalhado do mercado de banheiros préfabricados na Europa, Bonaccorsi (2015) estimou que o volume anual médio de banheiros produzidos no ano de 2015 no continente europeu foi de 128 mil unidades, o que representa uma indústria de 750 milhões de dólares por ano. Adicionalmente, estima-se que 250 mil banheiros pré-fabricados sejam manufaturados por ano no mundo e que, de todos os empreendimentos construídos no Japão, $80 \%$ utilizem esse sistema construtivo (MODULAR..., 2017). O reconhecimento da capacidade de aumentar a produtividade do setor também é reforçado pelo governo de Singapura, que em 2014 passou a exigir seu uso em ao menos $65 \%$ de todas as unidades de banheiros dos empreendimentos enquadrados no programa denominado Government Land Sales (SINGAPURA, 2014).

Adicionalmente, técnicas industrializadas podem criar outros benefícios não necessariamente monetários, mas que impactam de forma indireta os custos globais de um empreendimento (ANTILLÓN; MORRIS; GREGOR, 2014). Blismas, Pasquire e Gibb (2006) qualificam a situação em que não é feita uma investigação dos benefícios gerados, como "baseada em custos" (cost-based), e sugere que seja "baseada em valor" (value-based).Os seis casos pesquisados por esses autores demonstraram que métodos usuais de orçamentação são em sua maioria baseados em custos diretos. Um comparativo preciso entre sistemas construtivos convencionais e industrializados requer, portanto, uma análise baseada em valor.

O termo "valor" é empregado de forma ampla em contextos distintos, enquanto valor para o consumidor refere-se àquilo que ele quer e acredita conseguir ao adquirir produtos ou serviços da organização (WOODRUFF, 1997). Churchill e Peter (2000) sintetizam o conceito de valor para o consumidor como o resultado dos benefícios percebidos subtraídos dos custos percebidos. Tal conceito vem ganhando espaço, e, com isso, o processo de criação de valor deixa de ser papel exclusivo das organizações. Do ponto de vista acadêmico, Ranjan e Read (2014) pontuam que a criação de valor conjunta entre consumidores e organizações teve sua disseminação acelerada após os estudos de Prahalad e Ramaswamy (2000) e de Vargo e Lusch (2004). Para compreender tal processo, conhecido como cocriação de valor, Prahalad e Ramaswamy (2004) traçam um paralelo entre os conceitos de mercado tradicional e emergente. No primeiro caso, a criação de valor ocorria dentro da firma, com os consumidores alheios ao processo. O papel da firma era produzir, e o do consumidor, consumir. O mercado emergente, em contraste, é um espaço para trocas de experiências e criação conjunta de valor, ou seja, o consumidor deixa de ser passivo para atuar junto às organizações na definição e resolução de problemas.

Com foco em banheiros pré-fabricados, ainda incipientes no Brasil, nesta pesquisa o processo de cocriação de valor para consumidores foi conduzido durante rodadas Delphi. O estudo objetivou a identificação dos ganhos de valor atribuídos aos principais benefícios do sistema construtivo e serviu como etapa prévia para a criação de método para a quantificação dos valores atribuídos a seu principal benefício (SENGER, 2018).

\section{Método}

Foi adotado para a condução desta pesquisa o método Delphi, que é uma forma de avaliar e debater dados coletados em pesquisas quantitativas(HSU; SANDFORD, 2007). Seu objetivo é buscar o consenso entre um grupo de especialistas a respeito de um evento futuro. Para isso, são aplicados questionários interativos, os 
quais devem circular diversas vezes por um grupo de peritos, mantendo o anonimato dos respondentes. Os questionários devem ser respondidos individualmente, geralmente com respostasquantitativas apoiadas por justificativas e informações qualitativas. A cada rodada as respostas são tabuladas e recebem tratamento estatístico, para então serem devolvidas aos participantes para a rodada seguinte. As perguntas são mantidas nas etapas que se seguem, mas as respostas devem ser reavaliadas à luz do conjunto de respostas quantitativas e justificativas da rodada anterior. O processo é repetido até que as divergências entre opiniões sejam reduzidas a um nível satisfatório,de forma a considerar a última rodada como a previsão do grupo (WRIGHT; GIOVINAZZO, 2000).

A organização aqui proposta para esse procedimento técnico seguiu três grupos de atividades.Primeiro foram selecionados os especialistas. Em seguida, foram definidos o tema dos questionários, sua estrutura e demais atividades relacionadas. Por fim, elaborou-se o relatório final entregue aos envolvidos.

\section{Seleção dos especialistas}

De maneira distinta aos estudos de levantamento em que pesquisadores devem selecionar amostras cujo tamanho seja capaz de detectar estatisticamente os efeitos em uma população, os grupos escolhidos em técnicas Delphi não dependem de poder estatístico, mas da dinâmica para encontrar um consenso entre especialistas (OKOLI; PAWLOWSKI, 2004). Não há, contudo, consenso na literatura quanto à quantidade ideal de especialistas para estudos com essa técnica (HSU; SANDFORD, 2007). Rowe e Wright (1999) revisaram 27 artigos com uso da técnica, e as amostras variavam entre 3 e 98 especialistas. Alguns estudos variaram a quantidade de participantes e não chegaram a relações conclusivas. Por outro lado, a qualidade do resultado é influenciada pelo nível e especialização dos participantes (JOLSON; ROSSOW, 1971; RIGGS, 1983). Por exemplo, participantes pouco experientes podem ser incapazes de endereçar as afirmações mais importantes identificadas por especialistas (HSU; SANDFORD, 2007).

Por se tratar de um processo de cocriação de valor, os autores optaram por trabalhar com dois grupos de especialistas: consumidores e fornecedores. Tal escolha foi embasada de acordo com os seguintes raciocínios:

(a) são os grupos com envolvimento direto no processo executivo;

(b) possuem potencial acentuado de divergências opinativas, o que cria espaço para debates;

(c) são encontrados com mais facilidade; e

(d) fornecedores fazem produtos para consumidores, então é primordial que o valor percebido por ambos esteja alinhado.

Para esta pesquisa, adaptou-se o modelo de seleção apresentado por Okoli e Pawlowski (2004), ilustrado na Figura 1 e descrito nas subseções seguintes.

\section{Figura 1 - Procedimento para seleção dos especialistas}

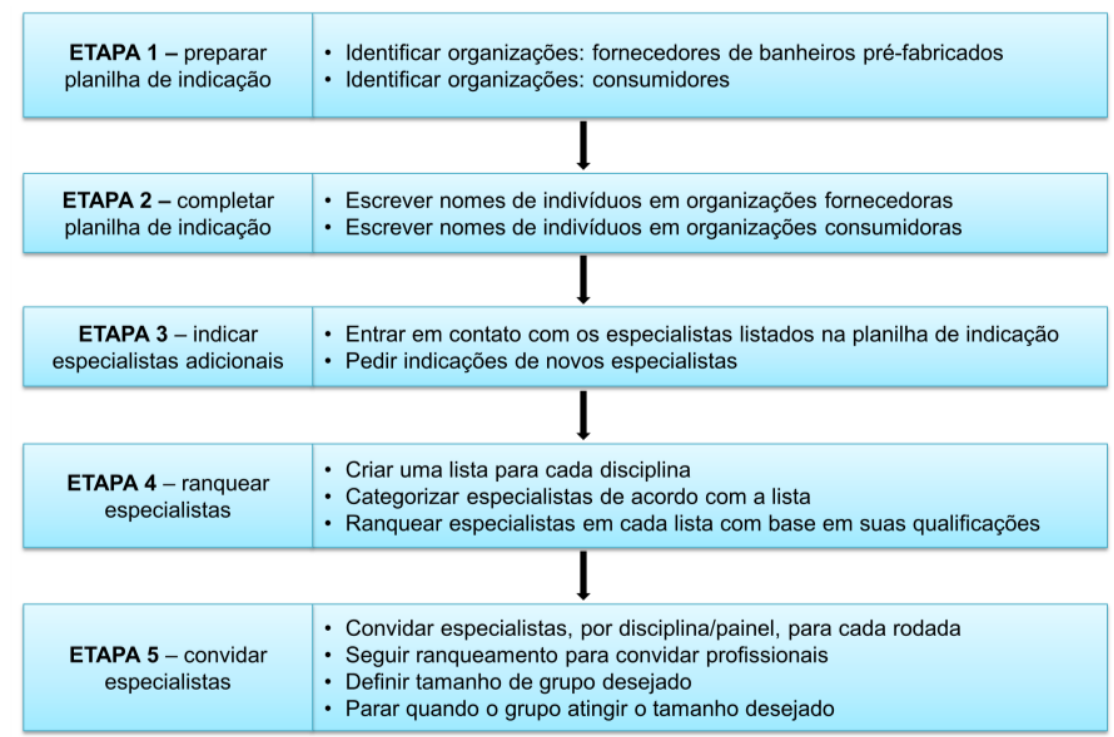

Fonte: adaptada de Okoli e Pawlowski (2004). 


\section{Etapa 1: preparar planilha de indicação}

O propósito da planilha de indicação ${ }^{1}$ é assistir a categorização de especialistas antes de identificá-los individualmente, a fim de evitar o esquecimento de classes importantes de participantes (OKOLI; PAWLOWSKI, 2004).

Foram listadas as organizações envolvidas na fabricação de banheiros pré-fabricados no Brasil, incluindo aquelas que já deixaram de existir. A investigação foi feita por sites de busca, redes sociais, listas de congressos, literatura nacional, buscas nos depósitos de patentes do Instituto Nacional da Propriedade Industrial (Inpi) e conversas com colaboradores e sócios dessas organizações. Os consumidores de banheiros pré-fabricados foram encontrados em sites de busca, redes sociais, reportagens e portfólio disponibilizado pelos fornecedores.

\section{Etapa 2: completar a planilha de indicação}

Esta etapa foi necessária para filtrar as categorias listadas. Para cada organização foram buscados nomes de indivíduos com potencial para participar da pesquisa. O procedimento de busca assemelhou-se ao da etapa anterior, com inclusão de contatos telefônicos e correio eletrônico. Definiram-se os seguintes critérios mínimos para inclusão de indivíduos:

(a) organizações fornecedoras:

- trabalhar ou ter trabalhado em organização(ões) que fornece(m) banheiros pré-fabricados;

- ter formação em engenharia e/ou assumir cargos da alta gestão; e

(b) organizações consumidoras:ter formação em engenharia e/ou assumir cargos da alta gestão relacionados à parte construtiva.

\section{Etapa 3: indicar especialistas adicionais}

Nesse ponto, os indivíduos listados na planilha de indicação foram contatados para indicar novos nomes para o estudo. O primeiro contato não foi um convite para participar das rodadas, mas no qual o estudo foi explicado - o funcionamento e os resultados esperados. Os indivíduos foram informados de que a pesquisa estava buscando participantes e que seriam contatados novamente assim que a base de indicações estivesse consolidada. Essa etapa garantiu a ampliação do leque de especialistas, em particular dos consumidores, cujos contatos e constatação das experiências foram de difícil acesso.

Delbecq, Van de Ven e Gustafson (1975) sugeriram que o processo de indicação tem um apelo de lisonjeio, pois os indivíduos sentem-se importantes ao serem cogitados como referências para indicação de novos participantes. O processo passa a criar um engajamento prévio que motiva o grupo.

\section{Etapa 4: ranquear especialistas}

Para cada grupo (fornecedores e consumidores) foram definidos critérios para posterior classificação do nível de expertise de cada participante. Baseando-se no modelo de organização das características de especialistas desenvolvido por Giublin (2002) e mantendo-se o anonimato dos participantes, as seguintes características foram avaliadas, sendo o maior peso atribuído à primeira, e o menor, à última:

(a) indivíduos de organizações fornecedoras:

- quantidade aproximada de banheiros pré-fabricados com que teve envolvimento;

- é engenheiro(a) ou arquiteto(a) e durante a atuação com banheiros pré-fabricados assumiu cargo de alta gestão;

- tempo de atuação com banheiros pré-fabricados;

- tempo de atuação com construção civil;

- atualmente trabalha com banheiros pré-fabricados; e

- teve experiência internacional com banheiros pré-fabricados.

${ }^{1}$ Tradução nossa: KnowledgeResourceNomination Worksheet. 
(b) indivíduos de organizações consumidoras:

- quantidade aproximada de banheiros pré-fabricados com que teve envolvimento;

- é engenheiro(a) ou arquiteto(a) e durante a atuação com banheiros pré-fabricados assumiu cargo de alta gestão;

- tempo de atuação com construção civil; e

- somatório dos seguintes processos em que esteve envolvido durante as contratações de banheiros préfabricados:

- processo decisório;

. compra;

- gestão/instalação; e

. pós-obra.

\section{Etapa 5: convidar especialistas}

O convite para participar da pesquisa foi iniciado pelos indivíduos com maiores pontuações na etapa 4. As técnicas de pré-fabricação de banheiros são pouco difundidas no cenário nacional, o que incorre em barreiras para acessar grande quantidade de especialistas no tema. Portanto, ficou estabelecido como meta angariar um grupo entre 10 e 20 especialistas.

A fim de garantir o sucesso do estudo, é essencial motivar o grupo. Para tal, Delbecq, Van de Ven e Gustafson (1975) citaram quatro características que devem ter os participantes:

(a) sentir-se pessoalmente envolvido no problema colocado;

(b) ter informações pertinentes para compartilhar (experiência);

(c) estar motivado para incluir o Delphi em sua agenda de tarefas; e

(d) sentir que os resultados incluem informações que não possui e que valoriza, mas não teria acesso sem o estudo.

Os dois primeiros itens foram endereçados a partir das etapas anteriores. Os itens "c" e "d", por sua vez, foram abordados durante os primeiros contatos, que esclareceram objetivos do Delphi, a natureza dos respondentes, as obrigações dos participantes, a duração do Delphi e a informação que seria compartilhada.

\section{Rodadas}

O método Delphi consiste em diversas rodadas, cada qual com um questionário específico até que um consenso seja estabelecido (Figura 2). O número de rodadas varia, pois depende da existência de consenso. Entretanto, a quantidade de rodadas costuma permanecer entre 3 e 5 (ROWE; WRIGHT, 1999). Como orientação para o processo, as rodadas foram baseadas na proposta de Hsu e Sandford (2007), adaptadas conforme evolução da pesquisa, todas envolvendo consumidores e fornecedores.

Figura 2 - Sequência de execução do método Delphi via internet

Envio via correio eletrônico

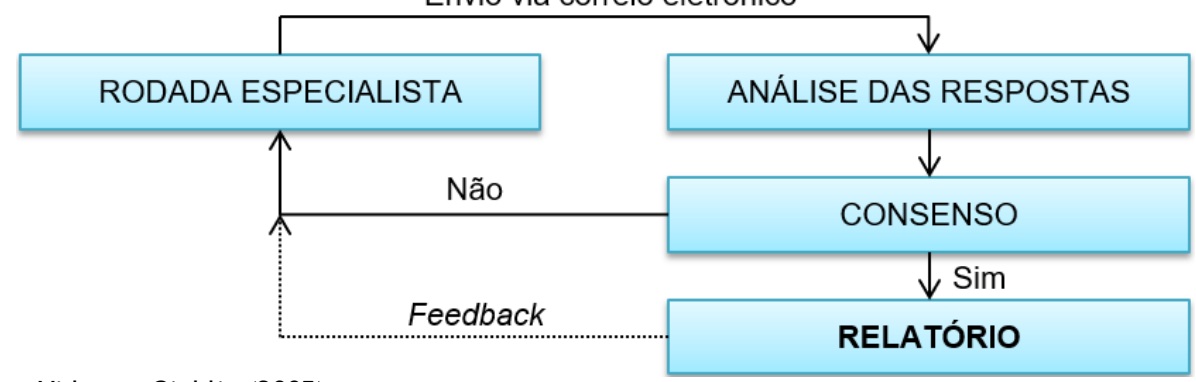

Fonte: Santos, Vidoto e Giublin (2005). 


\section{Primeira rodada}

Após o aceite dos especialistas, foi elaborado um e-mail explicativo com os pontos já tratados e um link para o primeiro questionário. Hsu e Sandford (2007) afirmam que o primeiro questionário é geralmente formulado com questões abertas para que criem base para estruturar questionários de levantamento. Em alguns casos, é aceitável e comum a modificação do processo Delphi para que sejam utilizados questionários estruturados, baseados em revisão extensiva da literatura, já na primeira rodada. Para a pesquisa, o primeiro questionário combinou questões abertas e fechadas e foi elaborado com a ferramenta Google Forms. A primeira questão apresentou um conjunto com os principais benefícios resultantes de uma revisão bibliográfica sistemática (RBS) (SENGER, 2018) e um levantamentocom construtores e incorporadores (SENGER, 2017), previamente elaborados pelos autores, dispostos de forma aleatória. A partir dessa lista, os especialistas selecionaram dez benefícios cujos valores gerados julgaram ser os mais relevantes para as técnicas de pré-fabricação de banheiros.

Em seguida, foram elencados os três benefícios principais. Pesos foram atribuídos segundo a colocação selecionada, em que $1^{\circ}, 2^{\circ}$ e $3^{\circ}$ lugares pontuavam 3,2 e 1 respectivamente. Partiu-se do raciocínio de que, ainda que um benefício seja atrelado ao método construtivo, o consumidor pode perceber certos benefícios como mais relevantes durante a tomada de decisão.

Por fim, para cada um desses três benefícios, os especialistas discorreram abertamente sobre as formas como agregariam valor para consumidores, doravante denominados "criadores de valor". A primeira rodada era requisito para participação nas demais e posterior recebimento do relatório final.

\section{Segunda rodada}

O questionário da segunda rodada foi personalizado para cada especialista. Composto de sete seções, as duas primeiras traçaram uma breve introdução e trouxeram um resumo dos resultados quantitativos gerais da primeira rodada, divididos em dois grupos:

(a) principais benefícios dos banheiros pré-fabricados; e

(b) benefícios que mais criam valor para o consumidor.

A Terceira seção - comparativo: benefícios listados na $1^{a}$ rodada - abordou o primeiro grupo de resultados e comparou os totais dos especialistas com suas marcações individuais. Em seguida, a quarta seção - alteração de benefícios listados na $1^{a}$ rodada - ofereceu a oportunidade de substituição de até quarto benefícios marcados durante a primeira rodada

A quinta seção explorou os criadores de valor. Estes foram agrupados por benefícios e apresentados para que o especialista definisse se concordaria ou não. Havendo discordância, um campo opcional para argumentação estava disponível.

Porfim, seguiu-se com procedimento análogo às seções de comparativo entre os benefícios listados na $1^{\mathrm{a}}$ rodada (terceiras eção) e de alteração de benefícios listados na $1^{\mathrm{a}}$ rodada (quarta seção), mas com foco no Segundo grupo de resultados.

\section{Rodadas seguintes e relatório final}

A partir da terceira rodada, o foco passou a ser exclusivo nos criadores de valor cujas opiniões haviam sido contra-argumentadas e/ou cujo consenso mínimo de $75 \%$ não havia sido atingido. Em um questionário único, todas as opiniões fornecidas em rodadas anteriores foram apresentadas para que os especialistas debatessem abertamente cada questão e, em vista dos argumentos expostos, revissem suas respostas. Com oencerramento da última rodada, foi elaborado um relatório final contendo informações gerais e os principais resultados do estudo.

\section{Cronograma}

Em função de sua natureza sequencial e iterativa, abordagens Delphi exigem intervalos longos (HSU; SANDFORD, 2007). Delbecq, Van de Ven e Gustafson (1975) sugeriram 45 dias como o intervalo total mínimo. No presente estudo, manteve-se um intervalo aproximado de 3 semanas entre rodadas. Tal decisão foi tomada para que a carga horária que os especialistas dedicavam à pesquisa fosse diluída e permitisse maior engajamento. Ainda, em função da definição de que a primeira rodada seria requisito para a continuação na pesquisa, estendeu-se o período de preenchimento àqueles que sinalizaram interesse em 
participar da pesquisa, mas que não conseguiram preencher o questionário no prazo estabelecido. Nesses casos, o preenchimento pôde ser efetuado até a conclusão da segunda rodada.

No ato do envio do questionário e em intervalos de 1 semana após o envio, contatos entre pesquisadores e especialistas foram estabelecidos. Assim, pôde-se verificar o recebimento dos questionários, bem como o surgimento de dúvidas, além de manter contato e acompanhar os especialistas que ainda não haviam registrado as respostas. As datas de cada contato (desconsiderando o contato no ato do envio) foram anotadas em uma planilha eletrônica para cálculo da taxa média de acompanhamentos por rodada/especialista.

\section{Resultados e discussões}

Após a análise de indivíduos de acordo com os critérios para a planilha de indicação (etapa 2), foram encontradas 9 organizações fornecedoras de banheiros pré-fabricados que atuam ou já atuaram no Brasil e 20 organizações consumidoras. Tentativas de contato por diversos meios foram estabelecidas durante a etapa 3 , e ao todo foram realizados 12 contatos bem-sucedidos com fornecedores e 9 com consumidores. Ainda que o total de organizações consumidoras listadas tenha superado em mais de duas vezes o de organizações fornecedoras, a obtenção dos dados dos indivíduos foi restrita. As percepções/constatações do pesquisador a respeito das possíveis justificativas para tal dificuldade foram:

(a) empreendimentos que adotaram o método já foram concluídos há anos e informações sobre as equipes envolvidas são escassas;

(b) por questões relacionadas à confidencialidade entre contratante e contratado, muitos fornecedores optaram por não repassar contatos;

(c) pouco material jornalístico cita diretamente indivíduos envolvidos na contratação de tal solução construtiva;

(d) dada a escassez de indicações de contatos diretos, muitas abordagens iniciais foram realizadas por meio de redes sociais ou diretamente com secretárias das organizações; e

(e) de maneira distinta do que ocorre com fornecedores, é limitada a relação consumidor-consumidor.

Dezessete especialistas concordaram em participar das rodadas Delphi. Apenas 13, entretanto, efetivamente responderam ao questionário inicial dentro do prazo estabelecido. Aos demais, manteve-se aberto o primeiro questionário até que a segunda rodada estivesse concluída. Nesse período, um dos especialistas completou o questionário, o que totalizou 14 participantes.

A classificação do nível de expertise dos participantes seguiu os critérios estabelecidos em 2.1.4 e está disposta na Tabela 1e na Tabela 2. Todos os 6 fornecedores participaram da fabricação de centenas de unidades de banheiros. O grupo contou com figuras de grande importância para o cenário nacional de banheiros pré-fabricados, com especialistas que ultrapassaram a marca dos 10 mil banheiros produzidos ao longo da carreira e um especialista cuja experiência com o sistema construtivo passa dos 40 anos. Além disso, todos os especialistas de organizações fornecedoras ocupam ou ocuparam cargos de alta gestão.

Tabela 1 - Ranqueamento dos especialistas participantes (fornecedores)

\begin{tabular}{l|c|c|c|c|c|c}
\hline $\begin{array}{c}\text { Quantas } \\
\text { unidades? }\end{array}$ & $\begin{array}{c}\text { Eng./ } \\
\text { Arq. }\end{array}$ & $\begin{array}{c}\text { Alta } \\
\text { gestão }\end{array}$ & $\begin{array}{c}\text { Atuação com } \\
\text { banheiro pré- } \\
\text { fabricado (anos) }\end{array}$ & $\begin{array}{c}\text { Atuação } \\
\text { com const. } \\
\text { civil (anos) }\end{array}$ & $\begin{array}{c}\text { Atualmente trabalha } \\
\text { com banheiro pré- } \\
\text { fabricado }\end{array}$ & $\begin{array}{c}\text { Experiência } \\
\text { internacional }\end{array}$ \\
\hline Acima de 10 mil & Sim & Sim & 40 & 40 & Sim & Sim \\
Acima de 10 mil & Sim & Sim & 15 & 16 & Sim & Sim \\
Entre 1 e 5 mil & Sim & Sim & 8 & 10 & Não & Não \\
Até mil & Sim & Sim & 5 & 20 & Não & Não \\
Até mil & Não & Sim & 5 & 20 & Sim & Não \\
Até mil & Não & Sim & 3 & 5 & Não & Não \\
\hline
\end{tabular}


Tabela 2 - Ranqueamento dos especialistas participantes (consumidores)

\begin{tabular}{l|c|c|c|c|c|c|c|c}
\hline \multirow{2}{*}{$\begin{array}{c}\text { Quantas } \\
\text { unidades? }\end{array}$} & \multirow{2}{*}{$\begin{array}{c}\text { Eng./ } \\
\text { Arq. }\end{array}$} & \multirow{2}{*}{$\begin{array}{c}\text { Alta } \\
\text { gestão }\end{array}$} & $\begin{array}{c}\text { Atuação } \\
\text { com const. } \\
\text { civil (anos) }\end{array}$ & $\begin{array}{c}\text { Erocesso } \\
\text { procisório }\end{array}$ & compra & $\begin{array}{c}\text { gestão/ } \\
\text { instalação }\end{array}$ & $\begin{array}{c}\text { pós- } \\
\text { obra }\end{array}$ & Total \\
\hline Acima de mil & Sim & Sim & 44 & Sim & Sim & Sim & Sim & 4 \\
Acima de mil & Sim & Sim & 40 & Sim & Sim & Sim & Sim & 4 \\
Entre 501 e mil & Sim & Sim & 15 & Sim & Sim & Sim & Sim & 4 \\
Entre 501 e mil & Sim & Sim & 8 & Sim & Sim & Sim & Sim & 4 \\
Entre 501 e mil & Sim & Não & 5 & Não & Não & Sim & Sim & 2 \\
Atén 500 & Sim & Sim & 18 & Não & Sim & Sim & Sim & 3 \\
Até 500 & Sim & Sim & 16 & Não & Não & Sim & Sim & 2 \\
Até 500 & Sim & Não & 5 & Sim & Sim & Não & Sim & 3 \\
\hline
\end{tabular}

A quantidade de unidades utilizadas por consumidores é relativamente inferior, o que é esperado, uma vez que empreendimentos levam anos desde a fase de planejamento à entrega e que a adoção desse método construtivo depende de uma ampla gama de fatores, não ocorrendo em todos os empreendimentos de uma organização. Ademais, usualmente profissionais atuam em poucas obras simultaneamente. Contudo, todos participaram de ao menos dois empreendimentos com banheiros pré-fabricados, tendo superado a marca de 300 unidades, e dois especialistas vivenciaram a execução de mais de mil unidades. Adicionalmente, todos os especialistas possuíam formação em arquitetura ou engenharia e, em ambos os grupos de organizações, todos os indivíduos tinham cinco ou mais anos de experiência profissional com construção civil.

\section{Resultado das rodadas}

A Tabela 3 fornece os resultados gerais da pesquisa,que teve duração de 67 dias entre o envio do primeiro questionário e o encerramento do recebimento de respostas da terceira e última rodada. Entre os 14 especialistas que participaram da primeira rodada, 6 foram classificados como fornecedores e 8 como consumidores. A taxa de resposta da primeira rodada foi de $82 \%$, seguida de $86 \%$ e $64 \%$. Cada especialista recebeu em média 1,64, 1,36 e 1,79 contato de acompanhamentos para a primeira, segunda e terceira rodada respectivamente. Tais valores indicam que, além do contato efetuado no momento do envio do questionário, ao longo do período entre rodadas, ao menos um acompanhamento precisou ser realizado. Ainda, a rodada só foi dada como encerrada após estabelecer no mínimo três acompanhamentos para especialistas que não haviam respondido.

\section{Benefícios dos banheiros pré-fabricados}

Os principais benefícios de banheiros pré-fabricados, independentemente do valor criado para consumidores, foram listados na primeira rodada e revisados na segunda. O resultado foi uma lista com 36 benefícios.

A maior convergência de opiniões ocorreu para redução de tempo de construção e certeza de custos, listados por $93 \%$ e $71 \%$ dos especialistas respectivamente, entre os dez principais benefícios. Empatados com $64 \%$ de convergência estão atendimento aos prazos, controle de qualidade melhorado, redução dos desperdícios da construção e redução de tempo. A maior qualidade do produto $(57 \%)$ e o custo minimizado de materiais (36\%) também figuraram entre os benefícios citados por mais de um terço dos especialistas. Cinco benefícios foram citados apenas uma vez, e outros doze foram citados duas vezes.

Entre os oito benefícios mais citados, sete fazem menção explícita à base da gestão de projetos: custo, tempo e qualidade. Esse fato pode significar preferência pelas análises quantitativas às qualitativas e o consequente posicionamento tradicionalista quanto ao desempenho de projetos, conforme revisado por Toor e Ogunlana (2010). Entretanto, houve citação de diversos benefícios que não se limitam a esses fatores, com destaque para a redução de desperdício na construção $(64 \%)$.

\section{Benefícios que mais criam valor para consumidores}

Sob o ponto de vista do consumidor, os benefícios elencados foram semelhantes àqueles listados na etapa anterior. Os sete principais benefícios permaneceram os mesmos, com pequena alteração na ordem de classificação para o benefício de qualidade do produto e o controle de qualidade melhorado, que alternaram as posições entre si. Ao todo, foram quinze benefícios considerados entre os três principais por ao menos um especialista (Tabela 4). 
Tabela 3 - Números gerais por rodada

\begin{tabular}{c|c|c|c|c|c}
\hline Rodada & Dias corridos & Envios & Respostas & Fornecedores/Consumidores & Acompanhamentos \\
\hline $1^{\mathrm{a}}$ & 19 & 17 & 14 & $6 / 8$ & 1,64 \\
$2^{\mathrm{a}}$ & 23 & 14 & 12 & $6 / 6$ & 1,36 \\
$3^{\mathrm{a}}$ & 25 & 14 & 9 & $5 / 4$ & 1,79 \\
\hline
\end{tabular}

Tabela 4 - Benefícios que mais criam valor para consumidores

\begin{tabular}{|c|c|c|}
\hline Benefício & Pontuação & Colocação \\
\hline Redução do tempo de construção & 18 & $1^{\mathrm{o}}$ \\
\hline Certeza do custo & 16 & $2^{\circ}$ \\
\hline Redução dos desperdícios da construção & 9 & $3^{\circ}$ \\
\hline $\begin{array}{l}\text { Atender aos prazos } \\
\text { Produto com maior qualidade } \\
\text { Reduzir tempo }\end{array}$ & 6 & $4^{\circ}$ \\
\hline $\begin{array}{l}\text { Controle de qualidade melhorado } \\
\text { Enfrentar falta de mão de obra }\end{array}$ & 4 & $5^{\circ}$ \\
\hline $\begin{array}{l}\text { Congelar o projeto em estágio inicial para melhor adoção da pré-fabricação } \\
\text { Construtibilidade } \\
\text { Maior qualidade para conexão e instalação }\end{array}$ & 3 & $6^{\circ}$ \\
\hline $\begin{array}{l}\text { Mão de obra mais qualificada } \\
\text { Redução do custo total do empreendimento }\end{array}$ & 2 & $7^{\circ}$ \\
\hline $\begin{array}{l}\text { Ambiente mais limpo } \\
\text { Uso mínimo do espaço em canteiro }\end{array}$ & 1 & $8^{\circ}$ \\
\hline
\end{tabular}

Nota-se que redução do tempo de construção e certeza do custo foram os principais benefícios para consumidores, ambos citados por 8 dos 14 especialistas e pontuando 18 e 16 respectivamente (Tabela 4). Alguns benefícios que haviam sido citados com frequência na etapa anterior não constaram como essenciais para a criação de valor. São eles:

(a) custo de materiais minimizado;

(b) integridade entre projeto e construção; redução de retrabalho; e

(c) redução da dependência de mão de obra desqualificada.

Destes, três haviam sido citados nas primeiras iterações, mas, após debates, foram substituídos.

\section{Criadores de valor}

Após a primeira rodada, 59 criadores de valor haviam sido listados, mas três não puderam ser debatidos pelo grupo porqueo preenchimento ocorreu durante o prazo extra concedido para a primeira rodada, ou seja, após o envio do segundo questionário. Em seguida, na segunda rodada, dos 56 criadores de valor, 16 receberam argumentações contrárias. Pôde-se notar, contudo, que grande parte dos criadores de valor obteve consenso após a primeira iteração, com 93,2\% de concordância média. Por fim, 14 desses criadores de valor e suas contra-argumentações foram levados à terceira rodada para aprofundar o debate.

O resultado, após modificação dos principais benefícios entre as rodadas 1 e 2, agrupamento de criadores de valor repetidos e a exclusão daqueles cujo consenso não atingiu $75 \%$, foi uma lista com 45 criadores de valor (Quadro 1).

\section{Debates: criadores de valor que não atingiram consenso}

Três criadores de valor não atingiram consenso, fato que implicou sua eliminação. Destes, dois atribuíram à redução do tempo de obra ganhos com redução de funcionários e padronização no acabamento. $\mathrm{O}$ terceiro criador de valor excluído sugere que a maior qualidade do produto implica redução dos chamados de assistência técnica e seus respectivos custos pós-venda. Nesse caso, os pontos negativos relacionam-se às experiências passadas de consumidores que tiveram de arcar com manutenções pós-obra, mesmo tendo optado por soluções industrializadas. Por outro lado, os argumentos favoráveis enfatizam maior qualidade na manufatura em função de fatores intrínsecos à industrialização, tais como ambiente controlado, emprego de 
equipes especializadas, rigor nos processos e controle de qualidade, bem como experiências positivas em que poucos chamados de assistência foram abertos após entrega do(s) empreendimento(s).

\section{Quadro 1 - Criadores de valor que atingiram consenso (Continua...)}

\begin{tabular}{|c|c|c|}
\hline Benefício & Criador de valor - Como gera valor para o consumidor? & Concordam \\
\hline \multirow{6}{*}{$\begin{array}{l}\text { Redução do } \\
\text { tempo de } \\
\text { construção }\end{array}$} & Maior possibilidade de diminuição de tempo de obra. & $100,00 \%$ \\
\hline & $\begin{array}{l}\text { Com menor período de obra, os dividendos do empreendimento } \\
\text { começam a retornar em menor tempo. }\end{array}$ & $100,00 \%$ \\
\hline & Com menor período de obra, os custos fixos da obra diminuem. & $100,00 \%$ \\
\hline & $\begin{array}{l}\text { A obra ganha um canteiro em paralelo, que é a fábrica de banheiros, } \\
\text { com isso o tempo é reduzido consideravelmente. }\end{array}$ & $100,00 \%$ \\
\hline & $\begin{array}{l}\text { Redução dos custos indiretos de obra e, no caso de um hotel, } \\
\text { antecipação da colocação no mercado, coletando antes o valor derivado } \\
\text { do aluguel dos quartos. }\end{array}$ & $100,00 \%$ \\
\hline & Menor efetivo de mão de obra em canteiro, pois a obra é mais rápida. & $91,67 \%$ \\
\hline \multirow{8}{*}{ Certeza do custo } & Falta de surpresas (leia-se gastos) ao longo do processo. & $100,00 \%$ \\
\hline & $\begin{array}{l}\text { Maior planejamento financeiro, evitando, assim, alterações no } \\
\text { orçamento. }\end{array}$ & $91,67 \%$ \\
\hline & Evitam-se surpresas, perdas de material e improdutividade. & $100,00 \%$ \\
\hline & $\begin{array}{l}\text { É um produto com altíssima previsibilidade de custos, diferente da } \\
\text { construção convencional, em que muitas vezes a necessidade de } \\
\text { serviços adicionais e retrabalhos vai sendo "descoberta" ao longo da } \\
\text { construção. }\end{array}$ & $91,67 \%$ \\
\hline & $\begin{array}{l}\text { Elimina as variáveis sobre a compra de diversos insumos e mão de obra, } \\
\text { substituindo apenas pela compra de um item já industrializado. }\end{array}$ & $91,67 \%$ \\
\hline & Custo fixo/menor risco/maior controle. & $100,00 \%$ \\
\hline & $\begin{array}{l}\text { Com o custo fechado em contrato, o cliente tem a certeza de que vai ter } \\
\text { o produto no tempo certo e com o custo que contratou, sem nenhuma } \\
\text { surpresa. }\end{array}$ & $100,00 \%$ \\
\hline & Não terá surpresas desagradáveis e solicitações de aditivos contratuais. & $91,67 \%$ \\
\hline \multirow{3}{*}{$\begin{array}{l}\text { Redução dos } \\
\text { desperdícios da } \\
\text { construção }\end{array}$} & $\begin{array}{l}\text { O projeto é pensado no uso total dos materiais (pensando nos recortes } \\
\text { de revestimentos, tubos, conexões, elétrica). }\end{array}$ & $91,67 \%$ \\
\hline & $\begin{array}{l}\text { Com a fabricação em grande escala, o desperdício e retrabalho são } \\
\text { menores e os testes mais eficazes. }\end{array}$ & $100,00 \%$ \\
\hline & Redução de gastos inesperados ou gastos extras. & $100,00 \%$ \\
\hline \multirow{4}{*}{$\begin{array}{l}\text { Atendimento de } \\
\text { prazos }\end{array}$} & $\begin{array}{l}\text { Aumenta a previsibilidade do empreendimento por diminuir o número } \\
\text { de serviços, restrições e interações para o mesmo produto final } \\
\text { (banheiro). }\end{array}$ & $100,00 \%$ \\
\hline & $\begin{array}{l}\text { Permite produção em paralelo dos módulos de banheiro enquanto a obra } \\
\text { está nas etapas iniciais (estrutura). }\end{array}$ & $100,00 \%$ \\
\hline & $\begin{array}{l}\text { Maior possibilidade de que atenderão ao cronograma da obra, } \\
\text { transformando várias etapas de um serviço em apenas uma etapa. }\end{array}$ & $100,00 \%$ \\
\hline & $\begin{array}{l}\text { A montagem feita por uma empresa bem estruturada envolve muito } \\
\text { menos riscos de prazo do que a montagem por empreiteiros. }\end{array}$ & $91,67 \%$ \\
\hline \multirow{3}{*}{$\begin{array}{l}\text { Produto com } \\
\text { maior qualidade }\end{array}$} & Mais qualidade. & $100,00 \%$ \\
\hline & Maior satisfação do cliente final. & $91,67 \%$ \\
\hline & Maior potencial de retorno como cliente. & $91,67 \%$ \\
\hline \multirow{6}{*}{$\begin{array}{l}\text { Redução do } \\
\text { tempo }\end{array}$} & $\begin{array}{l}\text { Enquanto a obra é feita no canteiro, os banheiros são produzidos na } \\
\text { fábrica, ganhando-se o tempo que seria executado na obra. }\end{array}$ & $100,00 \%$ \\
\hline & Redução do tempo total de obra. & $100,00 \%$ \\
\hline & Redução do custo/valor global. & $75,00 \%$ \\
\hline & Não atrasar o cronograma do projeto como um todo. & $91,67 \%$ \\
\hline & Dar maior exatidão no cronograma de avanço físico da obra. & $83,33 \%$ \\
\hline & Ganhar tempo significa uma economia direta e indireta no canteiro. & $100,00 \%$ \\
\hline
\end{tabular}

582 Senger, E. W.; Santos, A. de P. L. 


\section{Quadro 1 - Criadores de valor que atingiram consenso (continuação)}

\begin{tabular}{|c|c|c|}
\hline \multirow{4}{*}{$\begin{array}{l}\text { Controle de } \\
\text { qualidade } \\
\text { melhorado }\end{array}$} & $\begin{array}{l}\text { Com a concentração da produção em fábrica, há melhor controle de } \\
\text { qualidade, garantindo melhor padronização da produção. }\end{array}$ & $100,00 \%$ \\
\hline & Reduz variabilidade em acabamentos e processos. & $100,00 \%$ \\
\hline & $\begin{array}{l}\text { No processo industrial o controle de qualidade é feito por etapas. Cada } \\
\text { etapa é conferida e liberada para continuar a etapa seguinte. }\end{array}$ & $100,00 \%$ \\
\hline & $\begin{array}{l}\text { No caso de o fornecedor ter bom controle de qualidade, a gestão final } \\
\text { de qualidade na obra é melhorada. A tendência é que uma produção } \\
\text { repetitiva e em linha seja de maior qualidade, mais padronizável e mais } \\
\text { fácil de ser controlada quando comparada à produção tradicional no } \\
\text { canteiro de obras. }\end{array}$ & $100,00 \%$ \\
\hline \multirow{4}{*}{$\begin{array}{l}\text { Enfrentar falta de } \\
\text { mão de obra }\end{array}$} & $\begin{array}{l}\text { Devido à incerteza no mercado de mão de obra qualificada podemos ter } \\
\text { paralisação no processo devido à falta de mão de obra. }\end{array}$ & $75,00 \%$ \\
\hline & $\begin{array}{l}\text { Eliminar problemas relacionados à busca de profissionais competentes } \\
\text { para execução dos serviços. }\end{array}$ & $75,00 \%$ \\
\hline & $\begin{array}{l}\text { Desgaste de tempo e dinheiro na procura e contratação de mão de obra } \\
\text { qualificada. }\end{array}$ & $75,00 \%$ \\
\hline & Reduz o custo direto e indireto com a contratação de mão de obra. & $91,67 \%$ \\
\hline $\begin{array}{l}\text { Congelar o } \\
\text { projeto em } \\
\text { estágio inicial } \\
\text { para melhor } \\
\text { adoção da pré- } \\
\text { fabricação }\end{array}$ & $\begin{array}{l}\text { Em projetos que contemplam investidores múltiplos, mudanças de } \\
\text { escopo acontecem constantemente, gerando retrabalhos e custo por } \\
\text { tempo incalculáveis. }\end{array}$ & $100,00 \%$ \\
\hline \multirow{2}{*}{ Construtibilidade } & Diminuição do tempo de obra. & $100,00 \%$ \\
\hline & Racionalização e otimização do processo construtivo. & $100,00 \%$ \\
\hline \multirow[b]{2}{*}{$\begin{array}{l}\text { Maior qualidade } \\
\text { para conexão e } \\
\text { instalação }\end{array}$} & Redução de problemas no pós-obra/custo de manutenção. & $83,33 \%$ \\
\hline & $\begin{array}{l}\text { Os itens são instalados num ambiente controlado, o que garante maior } \\
\text { qualidade e confiabilidade, fazendo com que os custos de manutenção } \\
\text { sejam reduzidos, observando-se que todos os itens de instalações } \\
\text { deverão ter a manutenção preventiva sempre em dia. }\end{array}$ & $100,00 \%$ \\
\hline $\begin{array}{l}\text { Redução do } \\
\text { custo total do } \\
\text { empreendimento }\end{array}$ & $\begin{array}{l}\text { Com a redução no prazo de construção, o custo indireto também é } \\
\text { reduzido. }\end{array}$ & $91,67 \%$ \\
\hline $\begin{array}{l}\text { Ambiente mais } \\
\text { limpo }\end{array}$ & $\begin{array}{l}\text { Em obras de processo convencional, há mais acidentes de trabalho do } \\
\text { que em obras pré-fabricadas devido à organização e à limpeza dos } \\
\text { ambientes de trabalho, evitando custos com perda de pessoal. }\end{array}$ & $100,00 \%$ \\
\hline
\end{tabular}

\section{Debates: criadores de valor que atingiram consenso}

Os debates concentraram-se em sete criadores de valor e são apresentados em três grupos:

(a) relação entre redução de tempo e redução de custo;

(b) enfrentamento da falta de mão de obra; e

(c) relação entre qualidade e pós-obra.

No grupo 1 (Quadro 2) foram registradas 17 argumentações para dois criadores de valor. No primeiro: redução de custo/valor global como resultado do benefício reduzir tempo (75\% de concordância); argumentos contrários alegaram que banheiros pré-fabricados são mais caros que métodos convencionais e que não necessariamente a redução do tempo implicaria uma obra mais barata. Em contraposição, argumentos favoráveis defendem que a redução de tempo pode significar agilidade no retorno financeiro, eliminação de custos fixos/indiretos (canteiro, equipe etc.) e outros custos que não chegam nem a ser contabilizados na obra convencional. Para o segundo criador de valor debatido:

(a) encurtamento do prazo de construção e consequente redução do custo indireto quando relacionado à redução do custo total do empreendimento (91,7\% de concordância); e

(b) a variabilidade de argumentos contrários mostrou a complexidade do tema. 
Quadro 2- Debates do grupo 1: redução de tempo x redução de custo

\begin{tabular}{|c|c|c|c|c|}
\hline Benefício & $\begin{array}{c}\text { Criador de } \\
\text { valor }\end{array}$ & Concordam & $\begin{array}{l}\text { Argumentações } \\
\text { contrárias }\end{array}$ & Argumentações a favor \\
\hline \multirow{4}{*}{$\begin{array}{l}\text { Redução do } \\
\text { tempo }\end{array}$} & \multirow{4}{*}{$\begin{array}{l}\text { Redução do } \\
\text { custo/valor } \\
\text { global. }\end{array}$} & \multirow{4}{*}{$75,00 \%$} & $\begin{array}{l}\text { Reduzir o tempo não } \\
\text { necessariamente reduzirá o } \\
\text { custo final da obra. }\end{array}$ & $\begin{array}{l}\text { Enquanto a obra está em fase de } \\
\text { construção, os banheiros estão sendo } \\
\text { industrializados, o que significa } \\
\text { reduzir o tempo da obra. Reduzir o } \\
\text { tempo de inauguração de um hotel } \\
\text { significa que o retorno financeiro para } \\
\text { o investidor será mais rápido. }\end{array}$ \\
\hline & & & $\begin{array}{l}\text { A questão de custos das } \\
\text { obras em que trabalhamos, } \\
\text { já que o valor é mais alto } \\
\text { que os banheiros } \\
\text { convencionais. }\end{array}$ & $\begin{array}{l}\text { Com a redução do tempo de obra, } \\
\text { custos indiretos são eliminados, como } \\
\text { instalações do canteiro de obra, } \\
\text { equipe de obra, etc. }\end{array}$ \\
\hline & & & \multirow{2}{*}{$\begin{array}{l}\text { O banheiro pronto } \\
\text { comparado ao banheiro } \\
\text { convencional é mais caro, } \\
\text { portanto o custo sempre } \\
\text { será maior, mesmo com a } \\
\text { economia dos custos fixos } \\
\text { e perdas. Mesmo assim é } \\
\text { uma alternativa viável } \\
\text { quando você tem problema } \\
\text { de canteiro reduzido e/ou } \\
\text { quando a viabilização da } \\
\text { operação do negócio } \\
\text { depender da antecipação } \\
\text { de retorno do investimento } \\
\text { por antecipação da entrega } \\
\text { da obra. }\end{array}$} & $\begin{array}{l}\text { Existem inúmeros custos que não } \\
\text { chegam nem a ser contabilizados na } \\
\text { obra convencional: tempo de mão de } \\
\text { obra com retrabalhos, desperdícios, } \\
\text { ociosidade, etc. Por esse motivo } \\
\text { acredito sim que temos redução de } \\
\text { custo impactando no valor final. }\end{array}$ \\
\hline & & & & $\begin{array}{l}\text { Reduzindo o custo fixo, há redução } \\
\text { global. }\end{array}$ \\
\hline \multirow{7}{*}{$\begin{array}{l}\text { Redução do custo } \\
\text { total do } \\
\text { empreendimento }\end{array}$} & \multirow{7}{*}{$\begin{array}{l}\text { Com a } \\
\text { redução no } \\
\text { prazo de } \\
\text { construção, } \\
\text { o custo } \\
\text { indireto } \\
\text { também é } \\
\text { reduzido. }\end{array}$} & \multirow{7}{*}{$91,67 \%$} & $\begin{array}{l}\text { O custo do } \\
\text { empreendimento aumenta. }\end{array}$ & $\begin{array}{l}\text { O ganho está na entrega antecipada do } \\
\text { empreendimento, que proporcionará } \\
\text { um retorno financeiro antecipado, } \\
\text { como no caso de locações de quartos } \\
\text { de hotéis ou salas comerciais. } \\
\end{array}$ \\
\hline & & & $\begin{array}{l}\text { Não obrigatoriamente os } \\
\text { valores de redução dos } \\
\text { custos fixos e indiretos } \\
\text { significam que houve } \\
\text { redução do custo total do } \\
\text { empreendimento. Agora, } \\
\text { se os ganhos financeiros } \\
\text { forem agregados no } \\
\text { comparativo, aí sim haverá } \\
\text { vantagens na instalação de } \\
\text { banheiros prontos. }\end{array}$ & $\begin{array}{l}\text { Equipe e canteiro de obras deixam de } \\
\text { gerar custo, ocasionando a redução do } \\
\text { custo indireto. }\end{array}$ \\
\hline & & & \multirow{5}{*}{$\begin{array}{l}\text { Um dos itens relevantes no } \\
\text { custo da obra é o custo } \\
\text { fixo; portanto, se o tempo } \\
\text { de obra é reduzido, o custo } \\
\text { será reduzido. Agora, } \\
\text { afirmar que há redução de } \\
\text { custo indireto, não posso } \\
\text { concordar sem uma análise } \\
\text { mais elaborada. }\end{array}$} & $\begin{array}{l}\text { Quanto maior o tempo do projeto, } \\
\text { maior o custo com indiretos }\end{array}$ \\
\hline & & & & $\begin{array}{l}\text { Não é uma verdade absoluta, pois } \\
\text { existem muitas variantes envolvidas } \\
\text { para cada obra, mas uma tendência } \\
\text { muito forte, pois existe uma gama de } \\
\text { custos que é diretamente proporcional } \\
\text { ao tempo de obra. } \\
\end{array}$ \\
\hline & & & & $\begin{array}{l}\text { Com um tempo menor de produção, } \\
\text { diminui o tempo de contratação e os } \\
\text { custos com funcionários. }\end{array}$ \\
\hline & & & & É bastante óbvio. \\
\hline & & & & Isso é óbvio. \\
\hline
\end{tabular}


Um dos especialistas alegou que o custo do empreendimento aumenta, contudo outros dois foram mais comedidos explicando que:

(a) para ter uma posição mais precisa sobre a redução do custo total, deve-se considerar, além da redução de custos fixos indiretos, os ganhos financeiros;

(b) menos tempo implica redução de custos indiretos, mas para afirmar que isso leva à diminuição do custo total uma análise mais elaborada precisaria ser feita.

Novamente, argumentos favoráveis defendem que a entrega antecipada proporciona retorno financeiro adiantado e que custos fixos indiretos deixam de existir, sendo que existe uma gama de custos que é diretamente proporcional ao tempo de obra.

Observou-se que as discussões reproduzidas nos dois criadores de valor do grupo 1 possuem argumentos similares. Tal semelhança ocorreu porque ambos vincularam a diminuição do tempo à redução do custo total do empreendimento, mesmo quando debatidas em campos de benefícios distintos. Ainda, as divergências de opiniões podem ser interpretadas como efeito da falta ou baixa adoção de ferramentas comparativas eficazes para sistemas convencionais e pré-fabricação de banheiros.

O primeiro debate do grupo 2 (Quadro 3) gira em torno da afirmação de que há incerteza na disponibilidade de mão de obra qualificada no mercado, podendo haver paralização no processo, e que a industrialização de banheiros reduziria esse risco (75,0\% de concordância). Foram registrados um argumento contrário e um favorável. Neste, o especialista alega que as indústrias de manufatura investem no treinamento de seu pessoal e buscam reter talentos, o que não ocorre nos canteiros de obra, onde equipes são desfeitas a cada empreendimento. Por outro lado, há o argumento de que as indústrias de banheiros também sofrem com a escassez de mão de obra no mercado. Um debate mais extenso (sete argumentações) seguiu para os três criadores de valor que atribuíam aos banheiros pré-fabricados um potencial de redução dos esforços/recursos para contratação de mão de obra no canteiro. Três argumentos condicionam os criadores de valor ao momento vivenciado pelo setor, considerando válidos somente em condições de escassez de mão e obra. Também havia argumentos favoráveis relacionados à centralização da contratação de diversos serviços em um único fornecedor.

Por fim, o grupo 3 (Quadro 4) trata de um criador de valor similar àquele que havia sido descartado por falta de concordância ao tratar do pós-obra. Nesse caso, entretanto, relacionou-se a maior qualidade para conexão e instalação com o pós-obra (83,3\% de concordância). Novamente, dois argumentos contrários refletem experiências negativas com o uso do sistema. Outros seis argumentos favoráveis foram computados, relacionando itens como controle rigoroso no processo, idoneidade e experiência dos fabricantes, e tipo de instalação, que usualmente é flexível (PEX).

\section{Conclusão}

A pesquisa conduzida consistiu em um processo de cocriação de valor entre consumidores e fornecedores de banheiros pré-fabricados, que puderam debater suas vivências e opiniões ao longo de três rodadas Delphi.O rigor na condução do procedimento de seleção de especialistas possibilitou a participação de profissionais renomados, cujas experiências somadas superavam 30 mil banheiros pré-fabricados no Brasil e no mundo. Ao seguir as etapas descritas, os especialistas permaneceram engajados e interessados a ponto de responderem aos três questionários, de participarem dos debates e de fornecerem indicações e informações gerais durante contatos telefônicos.

A partir de dois estudos prévios - um levantamento e uma RBS - foi possível adaptar uma lista com benefícios genéricos da construção industrializada para uma nova lista, com os principais benefícios atribuídos aos banheiros pré-fabricados. Durante as rodadas, constatou-se quea redução de tempo de construção é o principal benefício dos banheiros pré-fabricados, seguida da certeza de custo e da redução dos desperdícios da construção. Para cada benefício, os especialistas listaram e debateram seus criadores de valor, ou seja, formas como consumidores percebem o valor de tais benefícios. 
Quadro 3 - Debates do grupo 2: enfrentamento da falta de mão de obra

\begin{tabular}{|c|c|c|c|c|}
\hline Benefício & $\begin{array}{c}\text { Criador de } \\
\text { valor }\end{array}$ & Concordam & $\begin{array}{c}\text { Argumentações } \\
\text { contrárias }\end{array}$ & Argumentações a favor \\
\hline \multirow{6}{*}{$\begin{array}{l}\text { Enfrentar } \\
\text { falta de } \\
\text { mão de } \\
\text { obra }\end{array}$} & $\begin{array}{l}\text { Devido à } \\
\text { incerteza no } \\
\text { mercado de } \\
\text { mão de obra } \\
\text { qualificada, } \\
\text { podemos ter } \\
\text { paralização } \\
\text { no processo } \\
\text { devido à falta } \\
\text { de mão de } \\
\text { obra. }\end{array}$ & $75,00 \%$ & $\begin{array}{l}\text { A falta de mão de } \\
\text { obra qualificada é } \\
\text { um problema } \\
\text { independentemente } \\
\text { que seja um banheiro } \\
\text { pré-fabricado ou } \\
\text { tradicional. } \\
\text { Provavelmente } \\
\text { ninguém de vocês } \\
\text { teve a "sorte" de } \\
\text { produzir banheiros } \\
\text { em Recife. }\end{array}$ & $\begin{array}{l}\text { A indústria trabalha intensamente na qualificação } \\
\text { de profissionais. Muitos são formados dentro da } \\
\text { empresa com treinamentos e cursos, um } \\
\text { investimento no profissional para qualificar e } \\
\text { agregar valor. } \\
\text { O profissional que é formado dentro de uma } \\
\text { indústria e que tem um plano de carreira e } \\
\text { crescimento profissional torna-se fiel à empresa, } \\
\text { diferentemente do que acontece no canteiro de } \\
\text { obras, em que a cada término de obra, na maioria } \\
\text { das vezes, a equipe é desfeita e quando se inicia } \\
\text { uma nova obra é necessária a busca de novos } \\
\text { profissionais. }\end{array}$ \\
\hline & $\begin{array}{l}\text { Eliminar } \\
\text { problemas } \\
\text { relacionados } \\
\text { à busca de } \\
\text { profissionais } \\
\text { competentes } \\
\text { para } \\
\text { execução dos } \\
\text { serviços. }\end{array}$ & $75,00 \%$ & \multirow{5}{*}{$\begin{array}{l}\text { Na época em que } \\
\text { tínhamos obras de } \\
\text { Copa do Mundo e } \\
\text { Olimpíadas, este } \\
\text { item era verdadeiro. } \\
\text { No mercado atual } \\
\text { isso não acontece. }\end{array}$} & $\begin{array}{l}\text { Apesar de concordar, acho que não vivenciamos } \\
\text { isso atualmente, apenas em um momento mais } \\
\text { aquecido da economia. }\end{array}$ \\
\hline & $\begin{array}{l}\text { Desgaste de } \\
\text { tempo e } \\
\text { dinheiro na } \\
\text { procura e } \\
\text { contratação } \\
\text { de mão de } \\
\text { obra } \\
\text { qualificada. }\end{array}$ & $75,00 \%$ & & $\begin{array}{l}\text { Com a contratação da empresa de banheiros } \\
\text { prontos, você está contratando um pacote } \\
\text { multidisciplinar de profissionais especializados } \\
\text { em cada uma das áreas necessárias para a } \\
\text { execução do banheiro, sempre lembrando que, } \\
\text { como em qualquer mercado, existem empresas } \\
\text { com mais ou menos experiência, idoneidade, etc. } \\
\text { A contratação de cada uma das disciplinas } \\
\text { individualmente gerará sim mais trabalho, custo e } \\
\text { incerteza, ainda mais imaginando que serão mais } \\
\text { de seis contratos distintos a serem gerenciados em } \\
\text { todos os aspectos, quando com a utilização do } \\
\text { banheiro teremos somente um contratado. }\end{array}$ \\
\hline & \multirow{3}{*}{$\begin{array}{l}\text { Reduzindo o } \\
\text { custo direto e } \\
\text { indireto com } \\
\text { a contratação } \\
\text { de mão de } \\
\text { obra. }\end{array}$} & \multirow[t]{3}{*}{$91,67 \%$} & & $\begin{array}{l}\text { Discordo que o profissional que executa banheiro } \\
\text { pronto seja mão de obra especializada. Serão } \\
\text { usados os mesmos profissionais que executariam } \\
\text { no canteiro, o que acontece é que o processo } \\
\text { construtivo é diferente, é industrial. Será } \\
\text { necessário apenas um pequeno treinamento para } \\
\text { que os profissionais aprendam a atuar num local } \\
\text { de produção industrial. } \\
\text { Sim, a construtora irá contratar menos operários, } \\
\text { uma vez que a empresa contratada para executar } \\
\text { os banheiros prontos é que terá que fazer as } \\
\text { contratações. }\end{array}$ \\
\hline & & & & $\begin{array}{l}\text { No cenário atual eu discordaria de todos os itens, } \\
\text { pois temos mão de obra disponível no mercado e } \\
\text { com qualificação, mas não deixa de ser um risco } \\
\text { não encontrar colaborador qualificado para todas } \\
\text { as atividades. }\end{array}$ \\
\hline & & & & $\begin{array}{l}\text { Certeza de mão de obra qualificada é um item } \\
\text { bem complicado para administrar. O contratante } \\
\text { de banheiros prontos sem dúvida ameniza } \\
\text { bastante esse problema para sua gestão. } \\
\end{array}$ \\
\hline
\end{tabular}

586 Senger, E. W.; Santos, A. de P. L. 
Quadro 4 - Debates do grupo 3: qualidade x pós-obra

\begin{tabular}{|c|c|c|c|c|}
\hline Benefício & $\begin{array}{l}\text { Criador } \\
\text { de valor }\end{array}$ & Concordam & $\begin{array}{l}\text { Argumentações } \\
\text { contrárias }\end{array}$ & Argumentações a favor \\
\hline \multirow{6}{*}{$\begin{array}{l}\text { Maior } \\
\text { qualidade } \\
\text { para } \\
\text { conexão e } \\
\text { instalação }\end{array}$} & \multirow{6}{*}{$\begin{array}{l}\text { Redução de } \\
\text { problemas } \\
\text { no pós- } \\
\text { obra/custo } \\
\text { de } \\
\text { manutenção. }\end{array}$} & \multirow{6}{*}{$83,33 \%$} & $\begin{array}{l}\text { Tivemos muitos } \\
\text { problemas em obra } \\
\text { com a utilização do } \\
\text { sistema banheiro } \\
\text { pronto. }\end{array}$ & $\begin{array}{l}\text { O sistema de conexão utilizado em banheiro pronto } \\
\text { (PEX) é mais versátil e simples de executar } \\
\text { manutenção preventiva ou corretiva, mas } \\
\text { principalmente é mais confiável que o sistema de } \\
\text { construção convencional. }\end{array}$ \\
\hline & & & \multirow{5}{*}{$\begin{array}{l}\text { Tivemos uma } \\
\text { experiência muito } \\
\text { negativa no pós- } \\
\text { obra devido à } \\
\text { impermeabilização. }\end{array}$} & $\begin{array}{l}\text { Reduzem, pois como os banheiros e suas instalações } \\
\text { são feitas dentro de um processo controlado, a } \\
\text { qualidade tende a ser bastante superior, entretanto } \\
\text { problemas também podem ocorrer, e a manutenção } \\
\text { pode ser bastante complexa. Eu também presenciei } \\
\text { obras utilizando banheiros prontos com problemas. }\end{array}$ \\
\hline & & & & $\begin{array}{l}\text { Existindo um controle bem feito no local da } \\
\text { produção/execução dos banheiros prontos e o mesmo } \\
\text { controle no momento das ligações em obra, sim, } \\
\text { concordo que teremos menos problemas e redução no } \\
\text { custo de manutenção. Caso seja contratada uma } \\
\text { empresa que não tem esses controles, os problemas } \\
\text { de pós-obra ocorrerão. }\end{array}$ \\
\hline & & & & $\begin{array}{l}\text { Todo o processo de manufatura dos banheiros é } \\
\text { realizado em ambiente muito mais controlado } \\
\text { (galpão) do que quando realizado em obra. Isso } \\
\text { confere maior efetividade no controle da qualidade de } \\
\text { todo o processo, inclusive possibilitando testes de } \\
\text { desempenho prévios em cada unidade. Obviamente } \\
\text { que, se o fabricante dos banheiros não possuir } \\
\text { robustos métodos de controle, seja por falta de know- } \\
\text { how ou mesmo por imprudência, a característica } \\
\text { intrínseca à produção seriada em ambiente controlado } \\
\text { aqui discutida sozinha de nada adiantará sem o } \\
\text { correto respaldo técnico. }\end{array}$ \\
\hline & & & & $\begin{array}{l}\text { Quando o processo é bem aplicado, com materiais de } \\
\text { qualidade e feitos os testes devidos para detectar } \\
\text { possíveis falhas, sem dúvidas reduz. }\end{array}$ \\
\hline & & & & $\begin{array}{l}\text { Precisa definir qual tipo de material será utilizado. } \\
\text { Nem todos os PEX são de boa qualidade, como as } \\
\text { conexões. Então concordo que reduza, porém se } \\
\text { utilizado bom material. }\end{array}$ \\
\hline
\end{tabular}

Os resultados apresentados criam uma base de dados sem precedente, que aprofunda a base de conhecimento e atribui um olhar específico a um sistema construtivo que oferece potenciais ganhos ao setor da construção civil. Além disso, permite-se que pesquisadores utilizem os resultados para direcionar esforços à criação de artefatos para comparação entre sistemas construtivos, como foi o caso do método para quantificação do valor percebido ao reduzir o cronograma de obra com banheiros pré-fabricados, desenvolvido pelos autores no presente estudo.

\section{Referências}

ANTILLÓN, E. I.; MORRIS, M. R.; GREGOR, W. A value-based cost-benefit analysis of prefabrication processes in the healthcare sector: a case study. In: INTERNATIONAL GROUP FOR LEAN CONSTRUCTION, 22., Oslo, 2014. Proceedings [...] Oslo, 2014.

BLISMAS, N. G.; PASQUIRE, C.; GIBB, A. Benefit evaluation for offsite production in construction. Construction Management and Economics, v. 24, n. 2, p. 121-130, 2006. 
BONACCORSI, P. The European Bathroom Pod Industry Review 2015: simplifying the construction process. Iorque: Intelligent Offsite, 2015.

CHURCHILL, G. A.; PETER, J. P. Marketing: criando valor para o cliente. 2. ed. São Paulo: Saraiva, 2000 .

DELBECQ, A. L.; VAN DE VEN, A. H.; GUSTAFSON, D. H.The Delphi technique. In: DELBECQ, A. L.; VAN DE VEN, A. H.; GUSTAFSON, D. H. Group techniques for program planning: a guide to nominal groups and Delphi process. Glenview: Scott Foresman and Company, 1975.

GIUBLIN, C. R. Diretrizes para o planejamento de canteiros de obra de pavimentação de concreto. Curitiba, 2002. 175 f. Dissertação (Mestrado em Engenharia Civil) - Programa de Pós-Graduação em Engenharia de Construção Civil, Universidade Federal do Paraná, Curitiba, 2002.

HSU, C.; SANDFORD, B. A. The Delphi technique: making sense of consensus. Practical Assessment, Research \& Evaluation, v. 12, n. 10, p. 1-8, 2007.

JOLSON, M. A.; ROSSOW, G. The Delphi process in marketing decision making. Journal of Marketing Research, v. 8, n. 4, p. 443-448, 1971.

MODULAR BUILDING INSTITUTE. Saving time with modular bathroom pods. Charlottesville, 2017.Relatório técnico.

OKOLI, C.; PAWLOWSKI, S. D. The Delphi method as a research tool: an example, design considerations and applications. Information \& Management, v. 42, p. 15-29, 2004.

PRAHALAD, C. K.; RAMASWAMY, V. Co-opting customer competence.Harvard Business Review, v. 78, n. 1, p. 79-90, 2000.

RANJAN, K. R.; READ, S. Value co-creation: concept and measurement. Journal of the Academy of Marketing Science, v. 44, n. 3, p. 239-315, 2014.

RIGGS, W. E. The Delphi method: an experimental evaluation. Technological Forecasting and Social Change, v. 23, p. 89-94, 1983.

ROWE, G.; WRIGHT, G. The Delphi technique as a forecasting tool: issues and analysis. International Journal of Forecasting, v. 15, p. 353-375, 1999.

SANTOS, A.; VIDOTTO, L. S.; GIUBLIN, C. R. A utilização do método Delphi em pesquisas na área da gestão da construção. Ambiente Construído, v. 5, n. 2, p. 51-59, 2005.

SENGER, E. W. Método para quantificação do valor percebido por construtores e incorporadores para sistemas de banheiros pré-fabricados: redução do cronograma. Curitiba, 2018. 309 f. Dissertação (Mestrado em Engenharia de Construção Civil) - Programa de Pós-Graduação em Engenharia de Construção Civil, Universidade Federal do Paraná, Curitiba, 2018.

SENGER, E. W. Percepções de construtores e incorporadores sobre industrialização na construção civil em Curitiba. E-Tech: Tecnologias para Competitividade Industrial, v. 10, n. 1, p. 23-43, 2017.

SINDICATO DA INDÚSTRIA DA CONSTRUÇÃO CIVIL. Produtividade na Construção. São Paulo, 2015.

SINGAPURA. Building and Construction Authority. APPBCA-2014-16. Amendments to building control (buildability) regulations to further raise construction productivity. Singapura, 31 out. 2014.

TOOR, S. R.; OGUNLANA, S. O. Beyond the 'iron triangle': stakeholder perception of key performance indicators (KPIs) large-scale public sector development projects. International Journal of Project Management, v. 28, p. 228-236, 2010.

VARGO, S. L.; LUSCH, R. F. Evolving to a new dominant logic for marketing. Journal of Marketing, v. 68 , p. 1-17, 2004.

VOKES, C.; BRENNAN, J. Technology and skills in the construction industry. London: Commission for Employment and Skills, 2013. Technical report.

WOODRUFF, R. B. Customer value: the next source for competitive advantage. Journal of the Academy of Marketing Science, v. 25, n. 2, p. 139-153, 1997.

WRIGHT, J. T. C.; GIOVINAZZO, R. A. Delphi: uma ferramenta de apoio ao planejamento prospectivo. Caderno de Pesquisas em Administração, São Paulo, v. 1, n. 12, p. 54-65, 2000. 


\section{Agradecimentos}

Os autores registram seu agradecimento aos especialistas que dedicaram tempo e compartilharam suas experiências em prol dos objetivos desta pesquisa.

Agradecem também à Capes, por uma bolsa de mestrado.

Eduardo Werneck Senger

Departamento de Construção Civil, Centro politécnico | Universidade Federal do Paraná | Av. Coronel Francisco H. dos Santos, 100 | Curitiba -PR - Brasil | CEP 81530-000 | Tel.: (41) 3361-3110 | E-mail: eduardowsenger@hotmail.com

Adriana de Paula Lacerda Santos

Departamento de Engenharia de Produção, Centro politécnico | Universidade Federal do Paraná | Tel.: (41) 3361-3609 | E-mail: adrianapls@ufpr.br

Ambiente Construído

Revista da Associação Nacional de Tecnologia do Ambiente Construído

Av. Osvaldo Aranha, $99-3^{\circ}$ andar, Centro

Porto Alegre - RS - Brasil

CEP 90035-190

Telefone: +55 (51) 3308-4084

Fax: +55 (51) 3308-4054

www.seer.ufrgs.br/ambienteconstruido

E-mail: ambienteconstruido@ufrgs.br 